\title{
Bier spots and unilateral nevoid telangiectasia: more than just a coincidence ${ }^{*}$
}

\author{
André Pinho ${ }^{1}$ \\ Hugo Oliveira $^{1}$
}

\author{
Miguel Gouveia $^{1}$ \\ Ricardo Vieira ${ }^{1}$
}

Dear editors:

Twin spotting (didymosis) means the coexistence of discrete areas of skin in close spatial and temporal proximity, differing clinically and genetically from each other, and from the background skin. This is a type of mosaicism caused by somatic recombination. A growing list of previously unexplained skin conditions has been attributed to this phenomenon. ${ }^{1}$

We describe the case of a 12-year-old Caucasian female with numerous macular, ovoid, hypochromic lesions of about $5 \mathrm{~mm}$ on the dorsum of the left hand and arm. Some of the lesions were confluent, surrounded by erythematous, blanching skin. (Figures 1-3). These lesions were asymptomatic, began at birth and were induced by pendent position of the arm, disappearing a few seconds after its elevation.

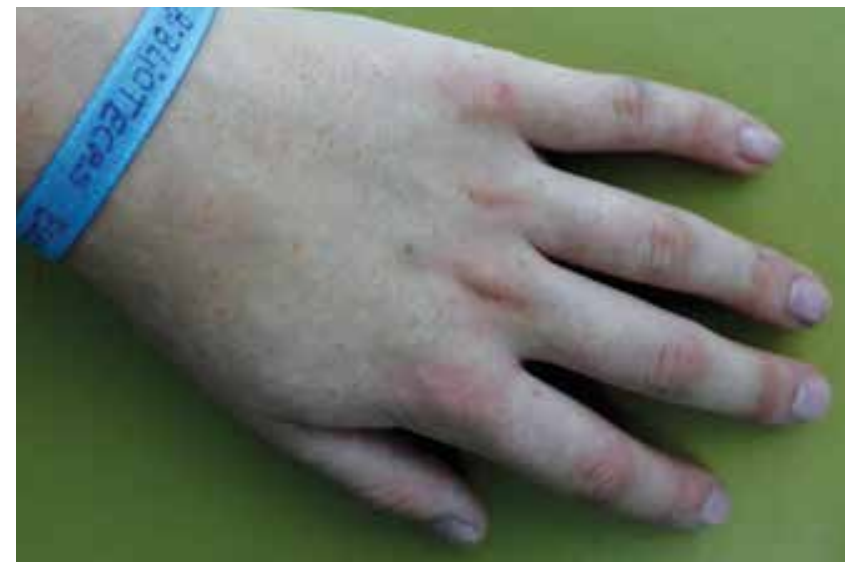

Figure 1: Hypochromic macules and fine telangiectasias on the dorsum of the left hand

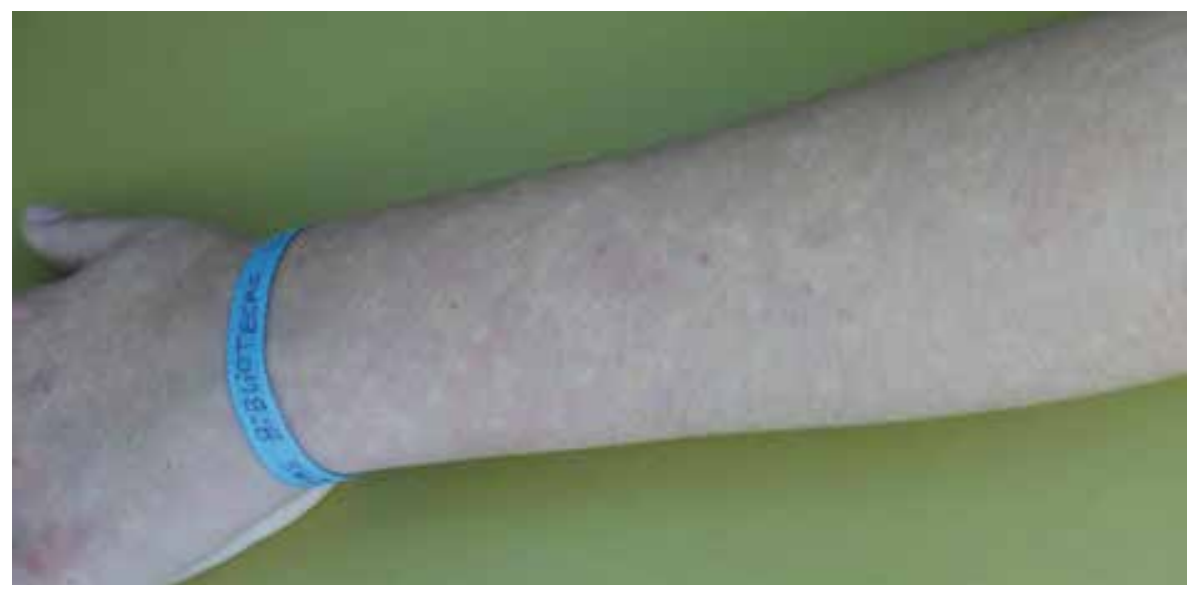

FIGURE 2: Lesions extending to the dorsum of the left arm

Approved by the Advisory Board and accepted for publication on 10.03.2015

Study conducted at the Department of Dermatology - Centro Hospitalar e Universitário de Coimbra - Coimbra, Portugal.

Financial Support: None.

Conflict of Interest: None.

1 Centro Hospitalar e Universitário de Coimbra - Coimbra, Portugal.

@2015 by Anais Brasileiros de Dermatologia 


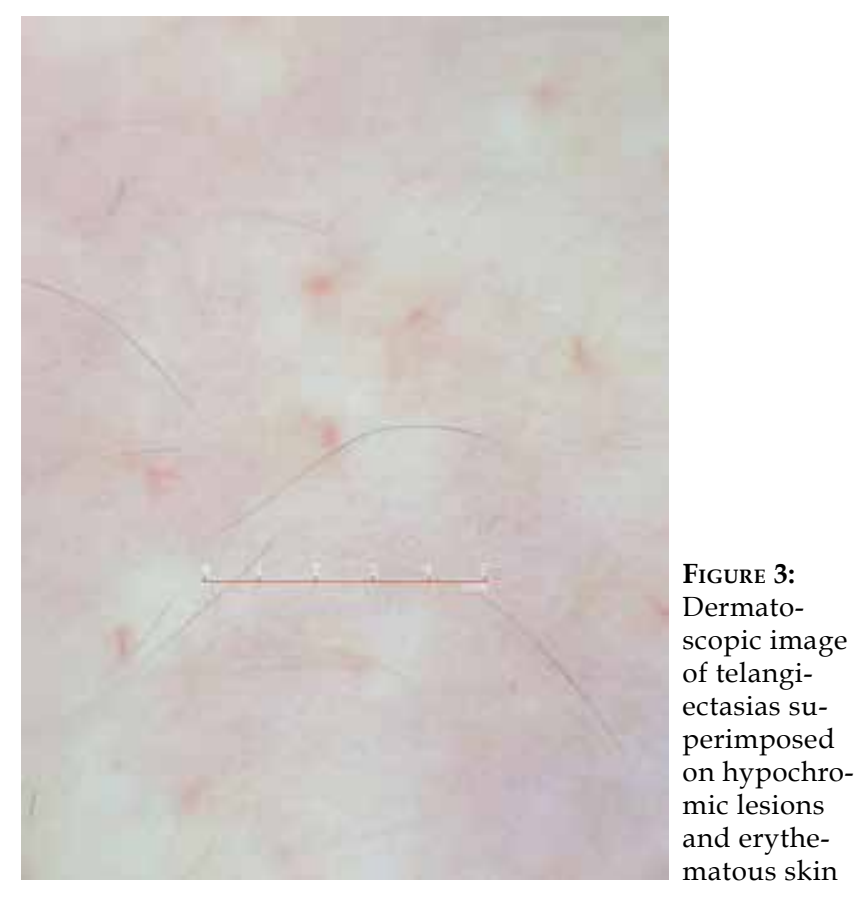

We also observed fine telangiectasia, with the same distribution, both within and outside the macular lesions. The telangiectasia did not change according to the position of the limb. There were no similar skin lesions in any other body areas.

Laboratory tests including complete blood count, coagulation studies, cryoglobulins, kidney and liver function tests, proteinogram, immunoglobulins, sedimentation rate, autoantibodies, thyroid function, sex hormones, urinalysis and serology for HIV and hepatitis were normal, as well as the Doppler ultrasound of the upper limbs.

In this case we assumed that the combination between hypochromic lesions compatible with Bier spots (BS) and unilateral nevoid telangiectasia (UNT)-like lesions could correspond to a phenomenon of vascular twin spotting, as we will highlight below.

The term vascular twin spotting was first used by Happle in 1990, to explain the occurrence of vascular twin nevi, i.e., the close spatial proximity between two functionally different vascular birthmarks: nevus flammeus and nevus anemicus. ${ }^{2}$

Eleven years later, Tan reported the first case of UNT superimposed on BS and considered that this dichotomy of vascular phenomena represented a new type of vascular twin spotting. ${ }^{3}$ To our knowledge, our case is the third report of this new type of mosaicism.

BS probably reflect an exaggerated vasospastic response to hypoxemia during venous stasis. Unlike this case, the limbs are usually affected symmetrical$1 y .{ }^{4} \mathrm{UNT}$ is characterized by unilaterally distributed superficial telangiectasias of the neck and chest, and indicate persistent vasodilatation. It is divided into congenital and secondary types (e.g., hyperestrogenism, which was not observed in this patient). ${ }^{5}$

The suggested mechanism of twin spotting considers that an embryo initially carries two recessive alleles at the same locus. These alleles control the vascular tonus. One is responsible for vasodilatation and the other is responsible for vasoconstriction. If crossing-over occurs in these chromosomes during mitosis, two distinct clones of homozygous daughter-cells might be generated. The homozygous lineage of the vasoconstriction allele leads to the development of BS, while the homozygous linage of the vasodilatation allele leads to the development of UNT lesions. ${ }^{2,3}$

The unilateral distribution of the lesions, which were located very closely together (and sometimes are superimposed on each other) and shared functional antagonism, led us to conclude that this was a case of vascular twin spotting.

This type of twin spotting is classified as "allelic", because recombination occurs between genes at the same locus. When genes of different loci recombine within the same pair of chromosomes, the twin spotting is called "nonallelic", as is the case in phakomatosis pigmentovascularis. ${ }^{1}$

\section{REFERENCES}

1. Koopman RJ. Concept of twin spotting. Am J Med Genet. 1999;85:355-8.

2. Happle R. Loss of heterozygosity in human skin. J Am Acad Dermatol. 1999;41:143-64.

3. Tan C, Zhu WY. Unilateral nevoid telangiectasia superimposed on the Bier spots: another demonstration of vascular twin spotting. J Dtsch Dermatol Ges. 2011;9:389-90

4. Liaw FY, Chiang CP. Bier spots. CMAJ. 2013;185:E304.

5. Jordão JM, Haendchen LC, Berestinas TC, Faucz LR. Telangiectasia nevoide unilateral adquirida em homem hígido. An Bras Dermatol. 2010;85:912-4.

\author{
MAILING ADDRESS: \\ André Pinho \\ Department of Dermatology \\ Centro Hospitalar e Universitário de Coimbra \\ Praceta Prof. Mota Pinto \\ 3000-075 Coimbra - Portugal \\ E-mail: andrecastropinho@gmail.com
}

How to cite this article: Pinho A, Gouveia M, Oliveira H, Vieira R. Bier spots and unilateral nevoid telangiectasia: more than just a coincidence. An Bras Dermatol 2015; 90(5):769-70. 